\title{
Christine Owen
}

\section{Academic Research and Creative Writing: Redrawing the Map and Finding One's Allies (and avoiding the Corbett phenomena)}

Barker: We all know our place, but what do we get out of it?

Cleese: I get a feeling of superiority over them.

Barker: I get a feeling of inferiority from him [Cleese], but a feeling of superiority over him [Corbett].

Corbett: I get a pain in the back of my neck. ('Three Men on Class' in Frost Report n.d.)

\section{Division in the Ranks?}

Some of you will no doubt remember the above iconic sketch, circa 1960s, in which a tall, upper-class, lean John Cleese looks down on the middling, stout Ronnie Barker, and Barker looks down on the diminutive, lowerclass Ronnie Corbett. Each gives his perspective on his role in the English class system:

Cleese: (In bowler hat, black jacket and pinstriped trousers) I look down on him [indicates Barker] because I am upperclass.

Barker: (Pork-pie hat and raincoat) I look up to him [Cleese] because he is upper-class; but I look down on him [Corbett] because he is lower-class. I am middle-class. Corbett: (Cloth cap and muffler) I know my place. I look up to them both. But I don't look up to him [Barker] as much as I look up to him [Cleese], because he has got innate breeding.

Cleese: I have got innate breeding, but I haven't got any money. So sometimes I look up [bends knees, does so] to him [Barker].

Barker: I still look up to him [Cleese] because although I have money, I am vulgar. But I am not as vulgar as him [Corbett] so I still look down on him [Corbett]. (Frost Report n.d.)

The humour in the sketch partly stems from the men's interdependency, but also from its ironic 'truth': a long English history in which rules of 'proper conduct' have functioned as barriers to social mobility. In this article I suggest that a similar kind of class comedy is at play in academia 
and, as such, the comedy sketch is a useful, if bizarre, introduction to this paper, which proposes that understanding the relationship of creative writing to other disciplines in the university might help improve the research of postgraduate creative writing students (and future academics).

Prestige tends to operate on the principle of exclusion, and on this basis creative writing has not always been as tolerated in the hallowed halls as it is now. In the 1970s, for example, John Sutherland (Fiction and the Fiction Industry 1978) observed, 'British universities will not touch creative writing' (cited in Stevenson 2004: 158). Robert Crawford, in his excellent discussion of the long relationship between creative writing and literature in English universities, suggests that such prejudice is not a modern phenomenon:

though the antagonism between poets and academia is nothing new, there may be a tendency to assume it is a phenomenon bound up only with recent developments in the teaching of English in universities. Commentators usually concentrate on post-war America, where the teaching of creative writing, composition, and literature sometimes exist uneasily together. (Crawford 2001: 13)

While the teaching of creative writing is now well established in most Western universities (with Oxford University being a notable exception), its wide acceptance belies the fact that many tensions remain. In Australia, Paul Dawson cites Ian Reid who, in arguing that 'the critical and the creative belong together', refers to 'barriers of silly prejudice which in this part of the world still separate "creative writing" from literary criticism' (Dawson 2004: 152). Part of the reason for this is that the practical arts are sometimes considered less important than the 'academic' Arts disciplines, such as history, literature and the relatively new cultural studies (a view partly perpetuated by the importance of research funding, as I will discuss).

In a 2003 research report on creative writing in English universities, in answer to the question 'Is teaching creative writing different from other disciplines?', one academic respondent replies somewhat defensively:

You'd think there's a class or species difference between English and creative writing teaching, but I don't feel there is. Basically you're trying to help people improve and gain skills. (May 2003: 61)

Many of the eighteen creative writing academics Steve May interviewed across a range of universities also felt the need to emphasise similarities between the English discipline and creative writing:

There are overlaps, in that you're asking people to assess the worth of material that they've produced, and a lot of that critical vocabulary is similar to the kind of critical vocabulary you use when you discuss canonical literature. (May 2003: 61)

The Enlightenment concept of the writer creating work based on his or her own individual talent has been a die-hard tradition that has affected perspectives of creative writing teaching in a range of areas, including assessment, the teaching of creativity and creative writing as a 'valid' vocation. Comments made in May's report suggest that creative writing assessment, affected by the idea of individual taste, is typically not 
understood outside discipline boundaries: 'At first there was a collective sense of indignation at the thought of work being graded, "how can they possibly mark creative work? It's a matter of taste, surely?"' (May 2003: 52). Influenced by the idea of individual creative talent, whether creative writing can be taught has also been a contentious issue, one raised by writers both inside and outside the academy. As one creative writing academic stated:

I think the bottom line is, you can't teach someone to be a writer, and you can't teach someone to be a painter, in the same way it's not something one chooses, as a creative practitioner, I didn't say, shall I be a poet, I don't know, or maybe an accountant. (May 2003: 55)

In addition to these cultural issues within the academy and within the discipline, the overall economic and political environment in which universities function affects the way that creative writing is perceived and received. My informal discussions with first year students indicate, for example, that parents often express concerns as to their choice of creative writing as one of their subjects; international students also tend to experience pressure from peers in more vocationally orientated courses, as well as their parents. May cites one academic reflecting on the difficulty he (or she) experienced in being open about their vocation:

I think there's an old romantic hangover that there's a romantic apartness about the writer which has prevented us from being open enough about it. When I started writing it was almost a secretive process. (2003: 57)

Overall, evidence which definitively establishes that creative writing and the creative arts occupy a kind of Corbett position in the university is difficult to establish in terms appropriate to a formal academic article. This is partly because the liberal culture of universities often produces an allinclusive rhetoric that seemingly welcomes all comers. Both within and without creative writing, there is also often a blindness to work being done in disciplines other than the one in which one works. Perhaps the most noticeable tensions arise however in relation to the area where a blind eye is rarely turned: research funding. As is well known, Arts disciplines are not as well funded as their wealthier counterparts in science or in the professions, including health, business, education and engineering. In this environment, the lack of flexibility in recognising creative work in research rankings, and therefore in research funding, is an ongoing rub for all academics in an environment in which Arts depend on a culture of ranking and competitive funding. It is hearsay evidence, but a kind of evidence nonetheless that, in my own university, in recent discussions concerning a proposal to increase the numbers of creative writing staff, the possible lowering of the department's overall research output on a per rata basis was raised as a problem that needed to be addressed.

In spite of these economic pressures and cultural tensions, changes in academia in the past forty years have supported the growth of creative writing, and changes within the Arts disciplines themselves now suggest that there might be more opportunities for creative writers to increase their research output by working collaboratively with other disciplines or, on the basis of their own research, by contributing to debates outside of their own discipline. In particular, opportunities may arise from the greater recognition of the importance of fictional and poetic writing by other disciplines. As Dawson observes: 
In a very real sense Creative Writing arose in opposition to the academic study of literature in departments of English because it demonstrated that literature could be deployed within universities in different professional and pedagogical ways than it had traditionally been; indeed, it could be deployed in other disciplines. (Dawson 2005: 127)

In general, the influence of postmodernism and post-structuralism has resulted in greater heterogeneity in what is considered to be appropriate academic writing, including fictocritical writing and an increasing recognition of the importance of creative writing in relation to expressing cultural, racial and gendered difference.

On this basis, I suggest, there is a need to provide postgraduates, in particular, with a 'map' of where creative writing sits within the university and what activity in other disciplines is allied to their own interests in order to develop stronger links with other areas. In John Cleese's class/war terms, the aim is perhaps to develop allies, build solidarity and, in doing so, storm the citadel (of research funding). Such a mapping could serve to counter lingering prejudice and enable creative writers to contribute more strongly to research. I argue that acquiring knowledge about 'where one is' within the university could avoid the feeling of being 'bunkered down by the perceived attitude of the academy to our research work' (Brady 2000). It could also prevent so many of us experiencing the Corbett phenomena, that is, 'a pain in the back of the neck'.

\section{Rewriting the Map}

When research and creative writing are discussed in the creative writing community, the discussion often revolves around ways to combine creative work with research or how to get creative work recognised as research. These areas are enormously important and there are interesting discussions on these topics throughout TEXT by Nigel Krauth, Jeri Kroll, Andrew Taylor and many others. There is in some of these discussions however a tendency to see academic work as less exciting and valid than creative work. Jeri Kroll sees the relationship between academic and creative as one of 'uneasy bedfellows' (Kroll 1999). Kevin Brophy uses the words 'pleasure' and 'pain' for creative work and academic work respectively (Brophy 1988: 218-19). Words like agony and even schizophrenia have been used to convey the tension between the two apparently incompatible parts. In this context, I recognise that in advocating a closer fit between the creative writing dissertation and work being done in other disciplines, I am at variance with a fairly wide-spread desire to have creative work exercise more influence over academic work. I argue that academic research, and creative writers' engagement in academic research, is not only an important part of the development of the creative writer and the creative process, but that research which critically investigates different aspects of creative writing potentially has an important role to play in research across the Arts, if not the university. On this basis, there is a need to provide a better, more useful 'map' of where creative writing as a discipline sits - and one possibility is a map drawn on the basis of the writing concerns common to a wide range of both arts and science disciplines. One might similarly draw a map linking disciplines with a focus on gender, race or class, or on genre, identity and representation. Similar disciplinary liaisons might be formed on the basis of common interest in different eras, for example. 
Creative writing sits within the Arts, itself is part of a larger bi-polarised universe, in which the Arts sometimes compare unfavourably with science and the professional disciplines in terms of status and funding. In the Arts, creative writing sits alongside more conventional academic disciplines such as history, anthropology, arts history, literary studies and the newer cultural studies among others. While all of might be considered 'lighter' than the more heavily endowed science-based disciplines, their strength is that in various ways, through theory, methodology and discourse, they often inform critical, self-reflexive discussions within the professional and science disciplines. For example, science has turned to theoretical ideas from the Arts to explain its dependence on narrative, to articulate professional issues such as ethics, and to understand communities and human behaviour. Increasing the sense of the interdependence within Arts and between Arts and other discipline areas creates a different sense of the university - not as a hostile landscape, but as a number of intersecting circles, where interesting and productive meetings can and do occur in the areas which overlap. It is in these intersecting circles that self-critical discussions about disciplinary practice and theory are typically fed by what is happening in other areas.

Most disciplines, some more than others, have critical and philosophical discussions about their own research and writing practices, and these inform debates across the university. In one example, the writing of history, or the sense that history has been written as different kinds of narrative, has mobilised many debates concerning the supposed neutrality of academic writing. This meta-discipline level of discussion, in this case historiography rather than history, enables all disciplines to talk to each other about mutual concerns. Discussions often develop in conferences and journals that focus on topics and historical periods, rather than on discipline areas per se (will the future see an interdisciplinary conference on the role of writing in cross-disciplinary research hosted by AAWP perhaps?). For creative writers, this kind of inter-disciplinarity potentially creates a space of dialogue capable of confounding a sense of 'us' and 'them'. In such a space, ideas can be considered, digested, tested, amended and fed back into intellectual debate - and back into practice. This is praxis at its best, not a new part of university life but a fundamental part of existing practice.

It is particularly important that creative writing students see the research they conduct, either in their dissertations or as part of their creative writing, as part of these webs of connection and influence, contributing to the debates which shape academic thought. The new postgraduate creative writers are often not aware of their participation in a dynamic field in which ideas are constantly circulated and critiqued. They are often not aware of the extent to which academic research is provisional: that is, others are expected to engage with your argument and amend your view; academic arguments circulate and are critiqued in a cycle of discussion that changes under the influence of ideas, culture and society. The problem of working without a dynamic sense of the university, working in fact, within a black-and-white, or creative versus academic, view is that neither of the polarised sides is challenged. Such a view leaves untouched the Romantic image of the writer as an isolated, creative individual and leaves untouched the idea of the academic as objective observer. This is a nineteenth-century model of thinking - 'Truth is to be discovered outside the rhetorical enterprise, through the method, usually the scientific method, of the appropriate discipline, or, as in poetry and oratory, through genius' (Russell 2002: 11) - which can no longer be supported. Such a dichotomy belongs in the past and our debates need to take into account 
the considerable shifts that have occurred in the academy in the past forty years, particularly around issues of narrative and writing.

\section{The Postgraduate Researcher}

For many students, writers and academics, there is no inherent conflict between being a good academic researcher capable of writing research papers, and a good writer producing a range of creative works. Both tasks have creative and critical aspects and both can equally produce pleasure and pain. Postgraduate creative writing students now frequently publish academic articles as part of their postgraduate training. Three of my own creative writing $\mathrm{PhD}$ students have chosen to do a $100 \%$ academic dissertation as opposed to the 50/50 creative/academic dissertation. All of them want to focus on their academic work because they feel this work will improve their creative writing. They tell me they are confident in their ability to keep developing their work as writers on the basis of their undergraduate training. One student chose to do a $100 \% \mathrm{PhD}$ dissertation because, although she was confident in her writing skills, she was less confident in her knowledge of literary history, which she said she would have liked more of at the undergraduate level. She said that when people heard she was a writer, they all assumed she knew about the Romantics, or about the Modernists. She wanted to study literature to put her own writing in perspective, to situate her generation of writers in relation to the long line of writers who had gone before, and to understand the different ways in which they had brought together different forms of writing with social and cultural issues. In the course of her research she has now read some philosophy as well as literary theory and is more familiar with the differences and similarities between literary periods. She is keen to become a creative writing academic and will make a fine one. She has already published an academic article and given a conference paper. Most importantly her judgment about not needing to do more creative writing study was in her case appropriate, as two years into her thesis, she has had a book of poetry published. Students such as these are clearly as excited by their academic work as their creative work. In this regard, I was interested to read that Helen Garner, recalling her university years, treasured the memory of the skills she learnt there: 'What I did learn ... was how to read. I loved close textual analysis (Garner n.d.). 'Love' is a word rarely used by creative writers in discussions about academic research. Yet I am sure many creative writing academics know of students who enjoy their academic work as much as their creative work - as a Masters student said to me recently, 'I hadn't expected my dissertation to be so enjoyable.' Are these students the nerds of the creative writing world? In that case, are we, as creative writing academics, unwittingly encouraging an antiintellectualism among postgraduate creative writers by not providing a way for students to understand how their academic research can be experienced as both relevant and enjoyable?

\section{Developing a Research course}

The discussion above explains the brief that I gave myself two years ago in creating a research subject for Masters by coursework students, a particular group, different in many respects to the $\mathrm{PhD}$ students coming from an Honours or Masters by Research path. These Masters by coursework students are on a $\mathrm{PhD}$ path, yet have chosen coursework to 
help them improve their creative writing as well as their academic writing. Many have never produced a substantial extended piece of academic writing. Some need some extra training in academic writing skills and, more widely, most do not understand what it means to be studying creative writing within an academic context. When I set up the research subject I addressed the dual need 1) to train students in undertaking and utilising research for their creative writing purposes and 2) to train the students with the research skills necessary to write their formal argument or dissertation (not the same as an exegesis which I understand to investigate the artistic process involved in producing the creative work). Where I work at the University of Melbourne the requirement is that both parts of the thesis should address the same research question.

The Research for Creative Writing subject is one of five in the Masters and it addresses the fact that many of these students express the desire to go on to do a $\mathrm{PhD}$, and as higher degree students and ultimately as academic staff they will also be applicants for research grants. Because of this academic environment, I took the view that their research training needed to develop skills to enable them to undertake both their creative work (for example, researching material for a novel) and their academic research (for example, research towards developing their argument). This perspective meant that the subject needed to expand their knowledge of academic concepts, in particular issues of representation and reading, and teach a broad range of research skills and methodologies. The subject aimed to make the students' creative work more effective, and to make the students more able, and potentially more collaborative, researchers.

My experience of postgraduate creative students is that the study of creative writing in the university is often vaguely thought of as achieving a higher level of creative writing skills. Students in fact often think that their writing skills will become more and more sophisticated the higher they rise in the tertiary system - it is as if at CAE level one is taught Volkswagen skills and at university Rolls Royce skills. However, clearly this is not the case and perfectly fine advice on creative writing is available in a range of institutions. What a higher degree can offer is more tailored advice on creative writing and, most importantly, access to a greater width, breadth and depth of ideas about literature, society and culture, as well as improved academic skills, increased intellectual knowledge, and research skills - including skills in writing in a variety of different genres. As creative writers and as academics, students will draw on a range of genres in the production of their writing. As well as the fictional genres, they need skills in writing the lecture, the conference paper, the journal article, the grant proposal, the book and the referee report. Understanding genre and the way it shapes meaning and reception is also a research skill. As such, in my research subject, I discuss genre in relation to the different kinds of writing they might encounter in their research and in their work.

The Masters by coursework postgraduates are important to this discussion because they express all the diversity of the creative writing tutorial. All of the students want to improve their creative work by working within an academic environment, but many are not at all are sure why, or what a university course might offer. Some come into the course saying that they know about writing (after many 'industry' courses) but their ideas feel stale and they want a challenge (and to be challenged). Some come as published writers who want to learn to think differently and produce different material. Others express the basic need for companionship and mentoring in the difficult and often lonely task of writing. Although many choose the 
course because it offers a route to a $\mathrm{PhD}$, and employment as an academic, most do not understand the research, supervision and teaching obligations of the creative writing academic.

At one level, teaching this coursework group about research is simply about making them more effective in their research as writers and, as the academic and poet Jordie Albiston states, in this regard, academic rigour itself can make a difference to their writing:

In the academic world, you can't afford to make many mistakes as such, or write assumptions into your work: everything has to be checked. You have to learn to retain the spelling of a particular name, or what year such-andsuch happened, or was said, or written. You have to. And hopefully that precision feeds back into the poems.

Academia also taught me how to research: where to begin, how to go about it. (Middleton 2001)

Some of the issues I have discussed explain why the Masters research subject has changed each year since its inception and has had a difficult path, the most common problem being that students do not generally understand the relationship between the critical and the creative.

Addressing such issues has led to a richer subject, and we have just had our most successful semester yet with the only complaint being the amount of material that the students (and the tutor) had to cover. In the Masters group, as in any postgraduate cohort, a substantial portion of students want to articulate stories based on their experiences and that of their own families. Their topics are many and varied, and include such phenomena as cross-cultural migration, issues of race, the Vietnam War and German incarceration in World War 2. The need for a research subject to assist students in their research originally came from my colleague and writer Marion M Campbell, who observed that while many students wanted to write research-based fiction, we weren't teaching them the research skills necessary to produce high quality, publishable work. The idea for a two-pronged approach came from other colleagues' frustration when, as supervisors of major projects, they had to address the fact that many of the students did not know how to go about their academic research. Consequently, the subject now has a two-pronged approach covering skills necessary to improve their creative writing research as well as skills to make them more effective as academic critics and researchers.

There is always a need at the beginning of a subject to be clear about course requirements, and for this particular subject it has been essential, partly because the students inevitably think that they are being led in two seemingly opposing directions - creative and academic. Due to this repeated difficulty, I rewrote the course this year with a different introduction and approach. I wanted to map for the students a way of thinking about their place as creative writing postgraduates within the academy. I (and their tutor, colleague Amanda Johnson) wanted them to rethink the way they saw their dissertation research. The idea was to get the students to appreciate how their creative writing dissertation might connect to research being done in other disciplines. By taking the 'map' and the 'hierarchy' as ruling metaphors, the subject now addresses what it means to be a postgraduate creative writer at the tertiary level, what a creative writing dissertation is and where they as creative writer researchers (in its fullest sense) sit within the university. The idea is to get the new postgraduate student to think of their study a little differently: to think of their dissertation as not only complementing their creative writing 
but also as informing, and being informed by, discussions and research into writing-related matters occurring across the university.

\section{One of a number of writing disciplines}

One of the ways in which a negatively perceived dichotomy between the academic and the creative can be addressed is through recognising that creative writing is one of a number of disciplines engaged in critical thinking about writing, narrative and creativity. On this basis, the students can be trained to recognise that the tools they draw on and the ideas they are interested in are, often, also the concern of other disciplines. Some of the broad shared concerns might include:

- Writing and observation

- Writing and archival research

- Reading and writing genre and discourse

- Writing, critique and analysis of narrative

- Conceptual analysis and the relationship between concept and metaphor

- Cultural study and critique

- Study of human behaviour and systems

- Writing, identity and difference

- Development, critique and use of different forms of representation and media

- Industry and discipline studies

Most significantly, discussions about the role of metaphor, narrative, and creative writing itself are now familiar to a range of disciplines. Although academic writing is sometimes critiqued and stereotyped as policing the use of first person narration, this is no longer a dominant concern in many disciplines. Many academics use creative writing as one of their tools and others recognise that narrative and metaphor have always been an important part of academic expression. In the last twenty years, disciplines that have held critical discussions about writing and which have utilised fiction and or narrative consciously as a research tool include science, economics, anthropology, history and philosophy. As economist DN McCloskey points out:

the economist like a novelist uses and misuses stories. Once upon a time we were poor, then capitalism flourished, and now as a result we are rich ... any economist tells stories. (McCloskey 1992: 1)

Postmodern and feminist thinking have been important influences on these discussions, and the pervasive role of fictocriticism has produced a range of 'collaborations' between academic and creative writing. In the field of history, many readers will be aware of the contributions of Hayden White and Dominick La Capra, among others. Most recently, in Is History Fiction?, Ann Curthoys and John Docker pick carefully over the rubble of the recent history wars and the ongoing debate on objectivity by reiterating that:

literary qualities and literary forms and genres are not something decorative or merely added to an account or analysis, but help explain what the historian in the present takes to be the meaning of past events and occurrences. (Curthoys and Docker 2005: 11) 
The list of scholars who have studied the metaphorical and narrative aspects of their disciplines includes Michele Le Doeuf whose important 1989 work, The Philosophical Imaginary, is a study of the importance of metaphor in shaping philosophic treatises. Marguerite La Caze in The Analytic Imaginary also refers to Paul Ricoeur as concerned with the way language calls things into existence. For Ricoeur, 'the creative imagination ... [has] the capacity to produce things which are non-existent, and the capacity to reproduce things which are absent' (Ricoeur 1977: 20). Like philosophy, science has not escaped recognition of the importance of writing to their discipline, and critics Latour and Woolgar observe that:

Even ... compulsive novelists are less obsessed by inscriptions than scientists. Between scientists and chaos, there is nothing but a wall of archives, labels, protocol books, figures, and papers. (Latour and Woolgar 1986: 245)

The list of Australian academics who advocate and write their work by combining creative and academic approaches in various disciplines is long and growing, including Greg Denning, Stephen Muecke, Michael Taussig, Paul Carter, Anne Brewster, Anna Gibbs and Robyn Ferrell.

Acknowledging the creative writing aspect of academic work is important because, as David Russell points out in Writing in the Academic

Disciplines, 'the invisibility of rhetoric itself [has] contributed to the low status of writing in the university' (Russell 2002: 17).

James Clifford in his landmark text Writing Culture (1986) was one of the first to show that storytelling could contribute to academic knowledge, albeit specifically in relation to ethnographic practices. Even while recognising that ethnographies are generically different from novels, he stresses the importance of fiction and rhetoric in the telling of stories from different cultures and societies. He depicts these stories as similar to works of literature in the sense that literary theory has redefined fiction as referring to 'the partiality of cultural and historical truths, the way they are systematic and exclusive.' Ethnography, he tells us, 'is artisanal, tied to the worldly work of writing' (Clifford and Marcus 1986: 6). Ethnographically speaking, creative writing itself might also be characterised as involving writing an experience that is 'Other' to their readers' experience, or involving a writer coming to terms with an experience that is 'Other' to their own. It typically involves making the familiar strange or vice versa. As Clifford writes, 'the story's unfolding requires us to first ... imagine a different cultural norm' (1986: 99). In this sense the writer like Clifford's ethnographer is '... a character in fiction ... at center stage. He or she can speak of previously "irrelevant" topics: violence and desire, confusions, struggles' (1986: 14). The ethnographer has the most difficult of tasks, but not one that is strange to the writer who also wishes the reader to experience something that, in its specificity, is unknown to them. As in academic research, creative writing itself stands on another writer's shoulders: 'Any story has a propensity to generate another story in the mind of its reader (or hearer), to repeat and displace some prior story' (1986: 100). Clifford is ambitious in his claims for the power of the story in academic life and he raises questions directly pertinent to our own discussions about creative writing research, when he argues:

Just as ... the realist novel served as the form for explorations of bourgeois manners and the self in early industrial society, so ethnic autobiography and autobiographical fiction can perhaps serve as key forms for 
explorations of pluralist, post-industrialist, late twentieth century society. (1986: 195)

In the overlapping circles in which debates about writing become possible between the disciplines, this is one area where creative writers can usefully contribute to the discussion.

\section{Conclusion}

The sense that creative writing is about individual creativity partly persists because writers are finally left alone with language, looking to express something in a different way, and in this solitary environment it is perhaps easy to overlook the sense that both difference and similarity (as well as familiarity) are ultimately contained by the broader culture in which we live. On this basis writers, including postgraduate researchers and creative writing academics, are clearly not isolated individuals, and for those fortunate enough to be writing within the university, their work is done in an often vibrant, intellectual, as well as worldwide community. I have sketched a sense of a newly mapped academic universe where allies present themselves at every corner of the campus; in this world the tools of creative writing have an important resonance, and the dissertation itself can become a bridge creating new connections between disciplines. For it is still the case that while many academics have taken up the challenge to combine fiction and academic work, not so many creative writers have taken up the challenge to contribute to academic debates about writing, narrative and metaphor, outside the creative writing discipline. Naturally, some writers' automatic response will be 'but that is not our job'; others might already have thought about the kind of research that creative writing postgraduates and future academics might produce to contribute to debates alongside the economist, the historian and the health scientist.

Understanding the map of the university as a dynamic force field in which ideas circulate between disciplines can contribute to improving the way postgraduates of all kinds can enjoy both their dissertation research and their creative writing research (without getting a pain in the neck). I put three comedians in place at the beginning of this paper to suggest prevailing perceptions about divisions between the creative writing discipline and other disciplines. The comedian's answers to each other revealed their mutual interdependence, as well as a long history of prejudice. Hopefully, in a more positive and productive way, creative writing academics can recognise the interdependencies between the creative writing discipline and other disciplines. In doing so they might be able to assist postgraduates to find a better way to think of their research, other than as a distraction from their 'real' creative work, by helping them to find a place to hold productive conversations with the many allies to be found among creative people across the university looking at the same kinds of issues from different perspectives.

\section{Works cited}

Brady, Tess 2000 'A question of genre: De-mystifying the exegesis', TEXT 4.1, April, http://www.griffith.edu.au/school/art/text Return to text

Brophy, Kevin 1988 Creativity: Psychoanalysis, surrealism and creativity, Carlton: Melbourne University Press Return to text 
Crawford Robert 2001 The modern poet: Poetry, academia, and knowledge since the 1750s, Oxford: Oxford University Press Return to text

Clifford James and George E Marcus (eds) 1986 Writing Culture: The poetics and politics of ethnography, Berkeley: University of California Press Return to text

Curthoys, Ann and John Docker 2005 Is History Fiction?, Ann Arbor: University of Michigan Press Return to text

Dawson, Paul 2005 Creative Writing and the New Humanities, Abingdon: Routledge Return to text

Freedman, Carl 2000 Critical theory and science fiction, Hanover NH: Wesleyan University Press.

Frost Report excerpt (n.d.), 'Three Men on Class', Chris Hughes's internet personal playpen, http://www.epicure.demon.co.uk/3men.html (accessed 15 June 2006) Return to text

Garner, Helen (n.d. [2005/2006]) English Dept Alumni webpage, University of Melbourne (accessed 31 August 2006) Return to text

Kroll Jeri 1999 'Uneasy bedfellows: Assessing the creative thesis and its exegesis', TEXT 3.2, October, http://www.griffith.edu.au/school/art/text/ Return to text

La Caze, Marguerite 2002 The analytic imaginary, Cornell: Cornell University Press Return to text

Latour, Bruno and Steve Woolgar 1986 The construction of scientific facts, Princeton: Princeton University Press Return to text

Le Doeuff, Michele 1989 The philosophical imaginary, London: Athlone Press Return to text

May, Steve 2003 Teaching creative writing at undergraduate level: Why, how and does it work? Project report, Bath Spa University College Return to text

McCloskey, DN 1992 If you're so smart: The Narrative of Economic Expertise, Chicago: University of Chicago Press Return to text

Middleton Kate 2001 'Interview with Jordie Albiston', Famous Reporter, No. 24,December, http://members.dodo.com.au/ ghannah/albiston.html (accessed 4 July 2006) Return to text

Ricoeur, Paul 1977 The rule of metaphor: Multi-disciplinary studies of the creation of meaning in language, Buffalo: University of Toronto Press Return to text

Russell, DR 2002 Writing in the academic disciplines, 1870-1990: A curricular history (2nd ed), Carbondale: Southern Illinois University Press Return to text

Stevenson, Randall 2004 The last of England? 1960-2000, Oxford: Oxford University Press Return to text

Sutherland, John 2001 'Just think of that', The Guardian, 12 March www.guardian.co.uk/Columnists/Column/0,5673,536887,00.html (accessed 31 August 2006) 
University of Melbourne. She studied history and social political theory at Murdoch University and has a PhD in literature and women's studies from the ANU. In addition to working as an academic, she has worked as a public servant and consultant. She writes short fiction and poetry and is currently working on a history / memoir and finalising a book manuscript on female castaway narratives in the eighteenth century.

\section{TEXT}

Vol 10 No 2 October 2006

http://www.griffith.edu.au/school/art/text/

Editors: Nigel Krauth \& Jen Webb

Text@griffith.edu.au 